\title{
Construction of Buildings and Structures on Rock Concrete Compensation Slabs when Building in Subsided Areas of Abandoned Coal Mines and Open Pits
}

\author{
Andrey Uglyanitsa ${ }^{1, *}$ \\ ${ }^{1}$ T.F. Gorbachev Kuzbass State Technical University, 28 Vesennyaya, Kemerovo, the Russian Fed- \\ eration
}

\begin{abstract}
For building in subsided areas of abandoned coal mines and open pits on soils damaged by anthropogenic impact and mining operations, it is proposed to base buildings and structures on a three-layer slab foundation including: a solid reinforced concrete foundation slab, a sub-ballast of ground overburden burnt rocks and a rock concrete compensation slab located between them. During subsidence of damaged soils, the rock concrete compensation slab, collapsing and increasing in volume, fills the sinkhole lens under the building with pieces of rock concrete, protecting the reinforced concrete foundation slab from destruction. It was experimentally established that for the production of rock concrete compensation slabs, cement rock concrete with aggregate of ground burnt rocks with a coarse fraction $(-20+10) \mathrm{mm}$ and a fine fraction $(-0.63) \mathrm{mm}$ should be used; the ratio of the percentage mass fraction of coarse and fine fractions being $25 / 75$ and 50/50 and the cement-water mass ratio $\mathrm{C}: \mathrm{W}$ being 1:0.5. The reinforced concrete compensation slabs of the recommended composition can take a design load of up to 9-11 $\mathrm{MPa}$ in dry and up to 8-9 $\mathrm{MPa}$ in water-saturated conditions. The use of ground overburden burnt rocks for the manufacture of rock concrete compensation slabs and sub-ballast will allow utilizing overburden burnt dumps and improving the environmental situation when building in subsided areas of abandoned mining enterprises.
\end{abstract}

\section{Introduction}

The significant areas of abandoned coal mines and open pits are damaged by mining and stoping operations. Subsidence and horizontal displacement of the earth's surface occur in subsided areas, leading to the deformation of buildings and structures up to their destruction. In addition, in such areas, in the upper zone of a soil base, as a rule, there is a layer of contaminated anthropogenic soil of a limited thickness, heterogeneous in composition, structure, physical and mechanical properties. It sags unevenly under the influence of the load from the building, causing the yield of the foundation and occurrence of critical destructive stresses in them.

\footnotetext{
*Corresponding author: uav@,Kuzstu.ru
} 
To reduce the values of the deformations of buildings and structures located on subsided soils, various structural measures are used that provide the spatial rigidity and the strength of buildings and structures, the stability of their structures and reliable connection of the elements with each other. Buildings and structures in such conditions, depending on their purpose and operation conditions, are designed according to rigid, yielding or combined structural schemes. The choice of the structural scheme is determined by need, nature and composition of the adopted structural protective measures.

Rigid structural scheme provides for the exclusion of the possibility of mutual movement of individual elements of the supporting structures during deformation of the soil base due to: separation of buildings and structures with expansion joints into separate compartments, reinforcement of individual elements of the supporting structures and the connections between them, installation of the reinforced concrete floor belts in the walls, construction of horizontal disks from reinforced concrete slab and floor units, building of foundations in the form of solid reinforced concrete foundation slabs, cross beams, beams, walls, etc. Rigid structural scheme is recommended for monolithic and large-panel cross-wall buildings and rigid load-bearing frame buildings. Yielding structural scheme provides for the possibility of adapting structures without occurrence of additional shear to uneven deformations of the earth's surface due to: installation of horizontal sliding joints in the underground part, introduction of articulated and yielding connections between the units of supporting and enveloping structures, etc. Such a scheme is recommended for braced frame buildings. When designing according to combined structural scheme, a combination of rigid and yielding schemes should be provided using various structural schemes of underground and superstructure parts of buildings and structures. Moreover, for all three structural schemes, if there is a layer of contaminated anthropogenic bulk soil of a limited thickness in the upper zone of the soil base, it is recommended to remove this layer and replace it with sand sub-ballast or reinforce it by the foundation.

The construction of a solid reinforced concrete foundation slab under a building or a structure when building in subsided areas of abandoned coal mines and open pits will be efficient with the implementation of both rigid and combined structural schemes [1-10]. A solid foundation slab resting on compacted sand sub-ballast will exclude uneven yield of building structures and the occurrence of critical breaking stresses in them. In addition, due to the large area of the support, a solid foundation slab will transfer insignificant pressure from the building to the subsided soil base, preventing the development of subsidence of damaged soils under the building.

The disadvantage of using a solid reinforced concrete foundation slab with a sand subballast when constructing buildings and structures on subsided soils is that in the event of a ground failure under the building, sand from the sand sub-ballast sags into this sinkhole and an empty space - a cavity - forms under the foundation slab. As a result, under the influence of the load from the building, tensile stresses arise in the foundation slab above the cavity, leading to its destruction.

In order to prevent the destruction of the foundation slab during the formation of a local cavity under it, due to subsidence of damaged soils under the building, it is proposed to place a concrete unreinforced compensation slab made of low-quality cement concrete between the foundation slab and the sand sub-ballast. In the event of local subsidence of soils under the sand sub-ballast, sand from the sand sub-ballast will fill the formed sinkhole lens and a secondary cavity will begin to form under the concrete compensation slab, which will lead to cracking and destruction of the concrete compensation slab.

At the same time, since the concrete volume increases during its cracking and destruction, a padding support is made of pieces of concrete at the site of the cavity that has formed, which will serve as a support for the reinforced concrete foundation slab, prevent- 
ing its destruction. Figure 1 shows the scheme of the concrete compensation slab operation during subsidence of the damaged soils under the building.

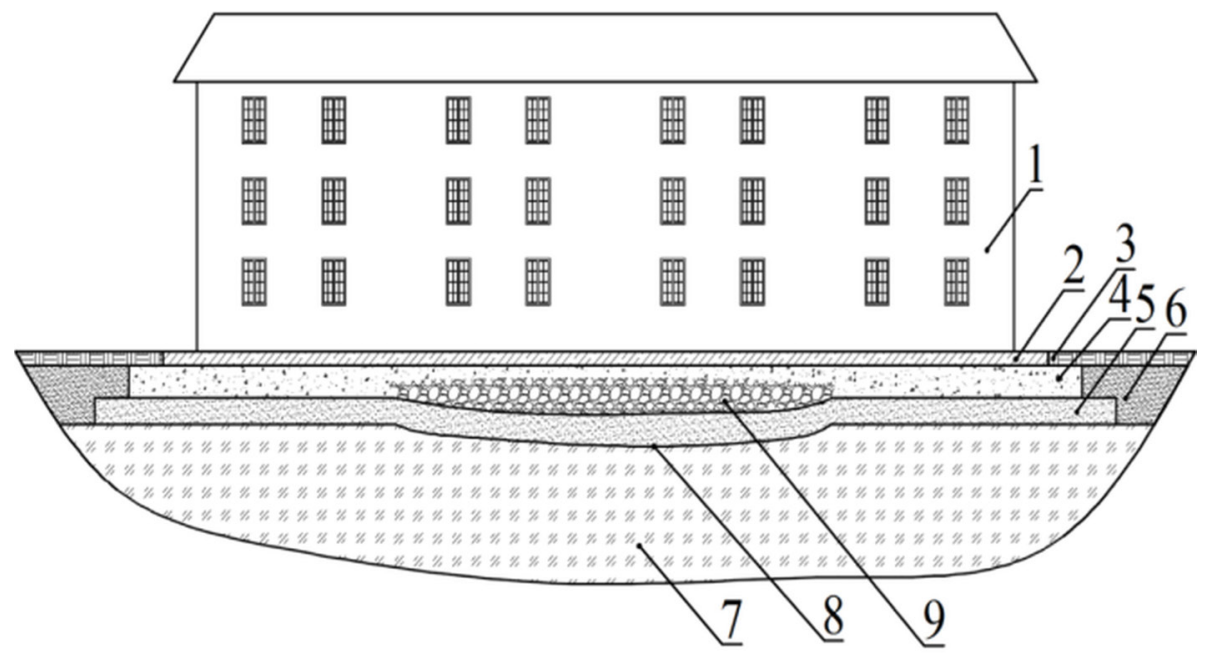

Fig. 1. The scheme of the concrete compensation slab operation during subsidence of the damaged soils under the building: 1- building; 2 - solid reinforced concrete foundation slab; 3 - soil; 4 - concrete compensation plate; 5 - sand sub-ballast; 6 - contaminated anthropogenic upper soil base layer; 7 - damaged soil base; 8 - sinkhole lens; 9 - padding support from pieces of cracked concrete.

In order to restore the protective function of the damaged concrete compensation slab, in case of subsequent subsidence of the damaged soil base, it is necessary to perform injection hardening of the cracked concrete of the compensation slab with cement-sand mortar through the wells drilled in the foundation slab.

For the manufacture of solid reinforced concrete foundation slabs, cement concrete of a grade of at least B22,5 is usually used, which corresponds to the compressive strength of concrete $\sigma_{\text {сж }} \approx 30 \mathrm{MPa}$. At the same time, the concrete strength of the compensation slab should be no more than 8-12 MPa, since concrete of the indicated strength will not shrink under a solid reinforced concrete foundation slab during the operation of the building, and will crack and increase its volume under it when the damaged soil base subsides.

The design of the proposed three-layer solid slab foundation should be made on the basis of well-known methods for designing a solid reinforced concrete foundation slab on subsidence and damaged soils. At the same time, the thickness of the concrete compensation slab for its efficient operation should be at least 1.2-1.5 $\mathrm{m}$ and determined depending on the predicted value of the possible subsidence of the damaged soils under the building.

However, a cement concrete compensation slab with of sand and gravel aggregate will have a high cost. A cheap and affordable aggregate for cement concrete is overburden burnt rock. The positive experience of using overburden burnt rock in the construction industry is described in the works of many researchers [11-15].

Given that abandoned coal mines always have overburden dumps, to reduce the cost of constructing concrete compensation slabs, as well as for the useful utilization of dump overburden burnt rock, researches have been carried out at KuzGTU to study the possibility of manufacturing concrete compensation slabs from cement concrete with aggregate from ground overburden burnt rock. 


\section{Result and discussion}

For the manufacture of samples of cement rock concrete from overburden burnt rocks, the following starting materials were used: binder - M400 grade Portland cement; aggregate overburden burnt rock from the dumps of the abandoned mine "Yagunovskaya" in the city of Kemerovo; water - tap water with a temperature of $+12^{\circ} \mathrm{C}$.

Since two-component (binary) mixture is mainly used as aggregate to produce cement concrete with a minimum cement consumption, a mixture of two fractions of ground overburden burnt rocks was used to produce rock concrete samples. In this case, the particles of the fine fraction fill the voids between the particles of the coarse fraction, which results in the formation of a dense aggregate mixture containing a large amount of solids and, therefore, a minimum amount of pore space.

Samples were made in standard detachable metal square molds with a size of $100 \times 100 \times 100$ $\mathrm{mm}$. Four standard fractions of ground overburden burnt rock, one coarse fraction with a size of $(-20+10) \mathrm{mm}$ and three varieties of fine fractions with a grain size of $(-2.5+1.25) \mathrm{mm}$, $(-1.25+0.63) \mathrm{mm}$ and $(-0.63+0.315) \mathrm{mm}$. The variation in the mass fractions in the sample was taken equal to $25 \%$, based on the principle of minimum sufficiency. The number of variations of samples of cement rock concrete from ground burnt rocks amounted to $12 \mathrm{pcs}$.

To produce rock concrete from ground overburden burnt rock, a cement mortar with cement-water mass ratio $\mathrm{C}: \mathrm{W}=1: 0.5$ was used, since it has a $100 \%$ yield of cement stone. The amount of the solution for producing the concrete mixture was taken to be equal to the void content of the aggregate mixture of ground overburden burnt rock, which was determined by filling with water a mold with a ground burnt aggregate of the studied particle size distribution. The concrete mixture was prepared in a laboratory mixer. Molded samples were stored during the day in molds at a temperature of $+20 \pm 2^{\circ} \mathrm{C}$. After stripping, the samples acquired strength at the same temperature and constant humidity of $100 \%$ for 28 days.

The compression strength of rock concrete samples was determined in dry and watersaturated state under a hydraulic press. When determining the strength of the samples, the average rate of increase in stress under a press was taken to be $0.2-1.0 \mathrm{MPa} / \mathrm{s}$, while the breaking load of the sample was within $20-80 \%$ of the maximum press force.

The test to reduce the compressive strength of water-saturated samples of cement rock concrete was carried out as follows. Samples were immersed in water and weighed every day with a frequency of 1 day. Weighing was carried out using an electronic balance with a measurement accuracy of $0.0005 \mathrm{~g}$. The process of saturation of samples with water lasted 12-18 days. The maximum absorption of water $(\approx 95 \%)$ occurred on the first day. In the remaining time, there was a uniform water saturation of samples at a rate of 1.2-1.8 $\mathrm{g} / \mathrm{day}$. After the weight of the sample was stabilized, it was tested for strength by the method used for dry samples.

The of rock concrete softening factor during its water saturation $K_{p}$ was determined as the ratio of the compressive strength of rock concrete in water-saturated state to the compressive strength of rock concrete in dry state.

In order to determine the required number of tests for identical (with the same particle size distribution) samples of rock concrete, as well as for further planning of experimental studies, ten samples were previously made from ground burnt rock with a fraction of $(-10+5) \mathrm{mm}$ and cement-water mass ratio $\mathrm{C}: \mathrm{W}=1: 0.5$. The arithmetic mean value of the compressive strength of rock concrete samples was $\sigma=4.15 \mathrm{MPa}$. The required number of samples with one particle size distribution for the accuracy of the result, equal to $90 \%$, was $\mathrm{n}=2.66 \pm 1.9$. Subsequently, in each series of experiments, we limited ourselves to testing three samples of rock concrete in dry and three samples in water-saturated states. A total of 72 samples were tested. 
The results of basic experimental studies to determine the compressive strength of rock concrete samples in dry and water-saturated states are shown in the table. Figure 2 shows the dependence of compressive strength of rock concrete samples in dry state on the size of the aggregate fractions and their content percentages.

An analysis of the results of experimental studies on the strength properties of cement rock concrete with aggregate from ground overburden burnt rocks showed that the compressive strength of rock concrete $\sigma$, depending on the size of the fractions of coarse and fine aggregates and their percentage, varies in the range 5.28-11.03 $\mathrm{MPa}$, and the of rock concrete softening factor changes, respectively, in the range of $0.66-0.88$ due to its water saturation $K_{P}$.

Table. The results of experimental studies to determine the compressive strength of rock concrete samples in dry and water-saturated states.

\begin{tabular}{|c|c|c|c|c|c|c|}
\hline \multirow{2}{*}{ Sample } & \multicolumn{2}{|c|}{ Fraction size, mm } & \multirow{2}{*}{$\begin{array}{l}\text { The ratio of } \\
\text { the content } \\
\text { of coarse } \\
\text { and fine } \\
\text { fractions }\end{array}$} & \multicolumn{2}{|c|}{$\begin{array}{c}\text { Sample compres- } \\
\text { sive strength } \sigma, \\
\mathrm{MPa}\end{array}$} & \multirow{2}{*}{$\begin{array}{c}\text { Softenin } \\
\text { g factor } \\
K_{p}\end{array}$} \\
\hline & $\begin{array}{l}\text { Coarse } \\
\text { fraction }\end{array}$ & Fine fraction & & Dry & $\begin{array}{l}\text { Water- } \\
\text { saturate } \\
\text { d }\end{array}$ & \\
\hline 1 & $-20+10$ & $-2.5+1.25$ & $75 / 25$ & 5.28 & 3.48 & 0.66 \\
\hline 2 & $-20+10$ & $-1.25+0.63$ & $75 / 25$ & 6.05 & 4.30 & 0.71 \\
\hline 3 & $-20+10$ & $-0.63+0.315$ & $75 / 25$ & 6.48 & 4.92 & 0.76 \\
\hline 4 & $-20+10$ & -0.315 & $75 / 25$ & 7.10 & 5.68 & 0.80 \\
\hline 5 & $-20+10$ & $-2.5+1.25$ & $50 / 50$ & 7.57 & 5.22 & 0.69 \\
\hline 6 & $-20+10$ & $-1.25+0.63$ & $50 / 50$ & 8.46 & 6.26 & 0.74 \\
\hline 7 & $-20+10$ & $-0.63+0.315$ & $50 / 50$ & 9.05 & 7.24 & 0.80 \\
\hline 8 & $-20+10$ & -0.315 & $50 / 50$ & 10.23 & 8.59 & 0.84 \\
\hline 9 & $-20+10$ & $-2.5+1.25$ & $25 / 75$ & 7.40 & 5.33 & 0.72 \\
\hline 10 & $-20+10$ & $-1.25+0.63$ & $25 / 75$ & 8.63 & 6.73 & 0.78 \\
\hline 11 & $-20+10$ & $-0.63+0.315$ & $25 / 75$ & 9.15 & 7.50 & 0.82 \\
\hline 12 & $-20+10$ & -0.315 & $25 / 75$ & 11.03 & 9.71 & 0.88 \\
\hline
\end{tabular}




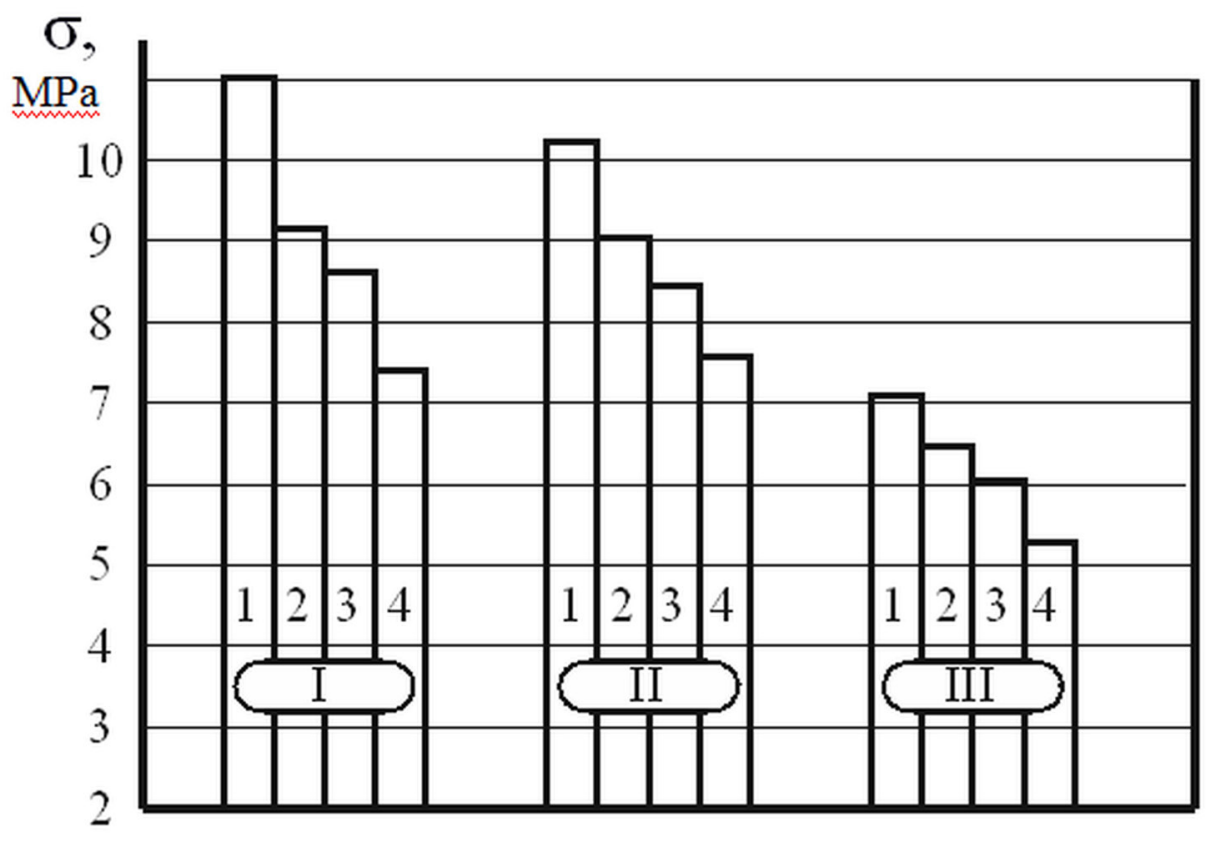

Fig. 2. The dependence of compressive strength of rock concrete samples in dry state on the size of the aggregate fractions and their content percentages: 1 - fraction $(-0.315)$;

2 - fraction $(-0.63+0.315) ; 3$ - fraction $(-1.25+0.63) ; 4$ - fraction $(-2.5+1.25)$; I, II and III - mass content percentages of coarse and fine fractions: I $-25 / 75$; II $-50 / 50$; III $-75 / 25$.

The lowest compressive strength values were obtained for rock concrete with a fine fraction size of $(-2.5+1.25)$ and $(-1.25+0.63) \mathrm{mm}$ with a ratio of the percentage mass content of coarse and fine fractions in rock concrete equal to $75 / 25$, and the highest values were obtained for rock concrete with a fine fraction size of $(-0.63+0.315)$ and $(-0.315) \mathrm{mm}$ with a ratio of the percentage mass content of coarse and fine fractions of 25/75 and 50/50. Therefore, for the production of rock concrete compensation slabs, cement rock concrete should be used with aggregate sizes of ground burnt rocks with a large fraction $(-20+10)$ $\mathrm{mm}$ and a fine fraction $(-0.63) \mathrm{mm}$, with a ratio of the percentage mass fraction of coarse and fine fractions $25 / 75$ and 50/50 and water-cement mass ratio $\mathrm{C}: \mathrm{W}=1: 0.5$. Compensation slabs of rock concrete of the recommended compositions can take a design load from buildings and structures up to 9-11 MPa in dry and up to 8-9 MPa in water-saturated conditions.

Given the high cost of sand, for the manufacture of sand sub-ballast, two-component mixtures of ground overburden burnt rocks with the recommended sizes of coarse and fine fractions and their percentage weight ratio should also be used.

\section{Conclusion}

1. For the construction of the areas of abandoned coal mines and open pits on soils damaged by anthropogenic impact and mining operations, it was proposed to place buildings and structures on a foundation including: a solid reinforced concrete foundation slab, a sand subballast of ground overburden burnt rocks and a concrete compensation slab located between them. During subsidence of damaged soils, the rock concrete compensation slab, collapsing and increasing in volume, fills the sinkhole lens under the building with pieces of rock concrete, protecting the reinforced concrete foundation slab from destruction. 
2. For the manufacture of rock concrete compensation slabs, a two-component mixture of aggregates from ground overburden burnt rocks with a coarse fraction $(-20+10) \mathrm{mm}$ and a fine fraction $(-0.63) \mathrm{mm}$ with a ratio of the percentage mass content of coarse and fine fractions $25 / 75$ and 50/50 and with a cement-water mass ratio $\mathrm{C}: \mathrm{W}=1: 0.5$ should be used.

3. Compensation slabs made of cement concrete with aggregate of ground overburden burnt rocks of the recommended composition can take a design load from buildings and structures up to 9-11 $\mathrm{MPa}$ in dry and up to 8-9 $\mathrm{MPa}$ in water-saturated conditions

4. The use of ground overburden burnt rocks for the manufacture of rock concrete compensation slabs and sand sub-ballast when building in the subsided areas of abandoned coal mines and open pits will allow utilizing overburden burnt dumps and improve the environmental situation in the areas of abandoned mining enterprises.

\section{References}

1. R. Bobe, G. Hertwig, H. Seiffert, Proc. of IX ICSMFE, 1, 411 (1977)

2. J. F. Gong, X. L. Huang, J. Teng, Proc. Of XVIICSMGE, 1, 1471 (2005)

3. J. F. Gong, X. L. Huang, J. Teng, Proc. of XVII ICSMGE, 5, 1997 (2009)

4. G. J. W. King, Z. E. Yao, The structural engineering, 61B(3), 62 (1983)

5. M. Leszezynski, Proc. of XVIIICSMGE, 5, 1263 (2009)

6. V. Sivaraman, Dept. of. Civil Engg.: I.I.T, 105 (1988)

7. Yi Fang Wang, Advanced Materials Research, 374, 1963 (2012)

8. R. Cajka, K. Burkovic, V. Buchta, Advanced Materials Research, 375, 838-841, (2014)

9. S. L. Tao, Z. F. Zhao, Z. H. Zhang, Advanced Materials Research, 273, 446-449 (2012)

10. S. D. Chandrakant, K. Tribikram, Press, 520, 67 (2001)

11. V. Maskaleva, V. Rybakov, Applied Mechanics and Materials, 842, 725-726 (2015)

12. G. I. Knigina, Bultuletinul institutului politehni, VI:3-4, 93 (1960)

13. J. G. Canibano, Coal Science, 1-2, 1629 (1995)

14. M. A. Cosca, E. J. Essene, J. W. Geissman, W. B. Simmons, D. A. Coates, Am. Mineral., 74, 85 (1989)

15. K. L. Scrivener, R. J. Kirkpatrick, Proceedings of the 12 International Congress on the Chemistry of Cement, 2, 358 (2007)

16. A. N. Ryazanov, P. E. Krizia, LNPU, 2, 3 (2009) 